\title{
TUPINISMO: UM ESTUDO SOBRE A IMPOSIÇÃO DA LÍNGUA GERAL AMAZÔNICA NO CONTEXTO BRASILEIRO
}

\author{
Airton Santos de Souza Junior ${ }^{1}$
}

\begin{abstract}
Resumo: Compreendendo por tupinismo o processo de imposição por meio da violência física de uma língua do tronco tupi, busca-se neste estudo demonstrar que os meios de implantação e propagação da língua geral amazônica ou nheengatu na Amazônia brasileira ocorreram de forma impositiva e coercitiva. Assim, toma-se como ponto de partida para as discussões as contribuições de Antezana (2014), Baniwa (2016), Fanon (2005), Freire (2011), Fonseca (2015), Hall (2016), Othero (2017), Silva e Isquerdo (2009) e Stessuk (2006). Desse modo, foi possível constatar que para além de uma língua supraétnica que permitira o contato entre povos de diferentes etnias, na realidade a língua geral amazônica foi, durante certo tempo, um forte instrumento utilizado segundo os interesses do sistema colonial, cuja imposição não deixou de ser arbitrária, coercitiva e violenta, desconsiderando assim as especificidades, identidades, singularidades e o direito de cada comunidade em manter sua própria língua.
\end{abstract}

Palavras chave: Língua geral amazônica. Mecanismos de propagação. Imposição linguística.

\section{Introdução}

Estudar a história de uma língua nos permite compreender alguns pontos que podem se mostrar relevantes para a compreensão de seu estado atual. Ao retomarmos o processo histórico anterior à independência do Brasil, compreendido e difundido em alguns livros de história como "período do descobrimento", estudiosos como Othero (2017) apontam que no período colonial havia no território brasileiro um vasto número de línguas faladas por comunidades indígenas, compreendendo um quantitativo aproximado em torno de 1.270 a 1.500 línguas.

Atualmente o número estimado dessas línguas decaiu consideravelmente, e daquele quantitativo superior a 1.000 línguas restaram um total aproximado de 180 línguas oficialmente catalogadas. As causas que levaram ao desaparecimento de tais línguas em solo brasileiro evidentemente não são as mesmas, mas no contexto Brasil colonial em que se destacam as maiores estimativas de perdas linguísticas, é possível apontarmos como ponto em comum

\footnotetext{
${ }_{1}^{1}$ Possui graduação em Letras Português pela Universidade Federal do Acre (UFAC), mestrando no Programa de Pós-Graduação em Letras: linguagem e identidade da UFAC, bolsista Capes. Professor substituto da área de Linguística/Língua portuguesa na UFAC.
}

Revista de Letras JUÇARA, Caxias - Maranhão, v. 03, n. 02, p. 128 - 142, dez. 2019| 128 
que todas as causas de "desaparecimento" linguístico estavam sob o mesmo contexto, fazendo, portanto parte da lógica de dominação que subjaz os sistemas coloniais (SAID, 2011).

Nesse sentido, não nos parece estranho pensar que sob o escopo da lógica de dominação colonial uma língua indígena possa ter sido utilizada como ferramenta a serviço dos interesses coloniais. Assim, e embora reconhecendo a pertinência da contribuição de Freire (2011) ao destacar em sua obra a relevância histórica da língua geral amazônica ou nheengatu, neste artigo buscaremos demonstrar os processos a partir dos quais a língua geral amazônica foi efetivamente implantada e propagada na região da Amazônia brasileira.

De modo, que buscamos esclarecer que apesar de a língua geral amazônica receber um considerável destaque, em especial na obra de Freire (2011), no que cerne a sua importância histórica para o Brasil, tendo em vista que na perspectiva do autor era uma língua que desempenhava um papel supraétnico permitindo a comunicação e interação entre pessoas de variadas nacionalidades, se nos voltarmos para os processos de implantação da língua geral amazônica poderemos constatar que de certo modo muito mais que desempenhar o papel de língua supraétnica e nativa, a língua geral foi uma poderosa ferramenta a serviço do sistema colonial, haja vista que em prol de seu uso muitas comunidades indígenas foram violentamente reprimidas e obrigadas a abandonar suas línguas nativas.

Sendo assim, e compreendendo, de acordo com Hall (2016), que a linguagem representa também um repositório de valores e significados culturais, entendemos que subtrair de uma comunidade a língua materna em detrimento de outra gera uma perda que não se restringe a substituição de códigos que permitem a comunicação, mas significa ainda e, sobretudo, uma perda de valores e significados culturais inerentes às vivencias particulares de uma comunidade.

Diante disso, demonstramos, portanto, que os meios de implantação e propagação da língua geral/nheengatu na Amazônia brasileira ocorreram de forma impositiva e coercitiva por meio da violência física, caracterizando o processo de colonialismo e não se diferenciando das demais ferramentas/formas de colonizar o outro - o que nos permite perceber que apesar de ser uma língua de origem indígena, diferentemente das demais, o modo como ela foi propagada 
não se deu de forma convencional no seio de comunidades de fala, mas sim de forma autoritária marcada pela violência dos corpos.

\section{Tupinismo}

Ao realizarmos uma busca pelas possibilidades semânticas da palavra tupinismo, podemos verificar em trabalhos como os de Antezana (2014), Silva e Isquerdo (2009) e Stessuk (2006), um sentido mais ou menos idêntico ao pontuado pelo Dicionário Houaiss da Língua Portuguesa (2009), que descreve o verbete tupinismo como palavra, construção ou mesmo locução da língua tupi, tomada de empréstimo por outra língua.

Portanto, podemos inferir que um dos sentidos comuns, senão o mais usual, atribuídos à palavra tupinismo, consiste no empréstimo de elementos específicos das línguas oriundas do tronco tupi, sejam elementos lexicais ou outros, sobre outras línguas. Assim, é que o estudo de tupinismos no português do Brasil diz respeito, por exemplo, aos empréstimos para a língua portuguesa de elementos linguísticos oriundos das línguas tupi.

Observa-se ainda que em paralelo com a palavra tupinismo surgem outras expressões como: tupinologia, que se refere ao estudo das línguas tupi; e tupinólogo, que neste caso indica o estudioso do tupi antigo, aquele que se propõe a investigar as marcas e mesmo influências do tupi sobre outras línguas, em síntese, o especialista em tupinologia.

Considerando esse significado aparentemente comum em relação à palavra tupinismo, nesse estudo propomos pensar o significado de tupinismo a partir de uma outra perspectiva, combinando morfologicamente o radical tupin mais o sufixo ismo da palavra colonialismo, nos levando, portanto, a compreensão do termo tupinismo como o processo de imposição de uma língua tupi sobre outras línguas, por meio da violência física.

Para entendermos melhor esse sentido que estamos propondo é importante que se parta do entendimento de que é o signo da violência, na perspectiva de Fanon (2005), a característica central que marca o colonialismo, tendo em vista que todo sistema colonial se mostra violento; violência esta, 
conforme aponta Fonseca (2015), que se inicia no próprio contato entre aquele que vem de fora e aquele que se encontra dentro de certo ambiente:

\begin{abstract}
A violência colonial não tem somente o objetivo de garantir o respeito desses homens subjugados; procura desumanizá-los. Nada deve ser poupado para liquidar as suas tradições, para substituir a língua deles pela nossa, para destruir a sua cultura sem lhes dar a nossa; é preciso embrutecê-los pela fadiga. Desnutridos, enfermos, se ainda resistem, o medo concluirá o trabalho: assestam-se os fuzis sobre o camponês; veem civis que se instalaram na terra e o obrigam a cultiva-la para eles. Se resiste, os soldados atiram, é um homem morto; se cede, degrada-se, não é mais um homem; a vergonha e o temor vão fender-lhe o caráter, desintegrar-Ihe a personalidade. (FANON, 2005, p. 09).
\end{abstract}

Nesse sentido, observamos que todo o contexto colonial é construído a partir do signo da violência, que visa não somente garantir o respeito e subserviência daqueles que se encontram subjugados, mas também objetiva a desumanização desses, de maneira que quanto a esta "meta" a ser atingida pelo colonizador, nada e nenhum esforço devem ser poupados para extirpar dos povos subjugados suas tradições, línguas e identidades, destruindo assim sua cultura sem, contudo, entregar-Ihes a do colonizador.

\begin{abstract}
Nas regiões coloniais, ao contrário, o gerdame e o soldado, por sua presença imediata, por suas intervenções diretas e frequentes, mantém contacto com o colonizado e o aconselham, a coronhadas ou com explosões de napalm, a não se mexer. Vê-se que o intermediário do poder utiliza uma linguagem de pura violência. $O$ intermediário não torna mais leve a opressão, não dissimula a dominação. Exibe-as, manifestaas com a boa consciência das forças da ordem. O intermediário leva a violência a casa e ao cérebro do colonizado. (FANON, 2005, p. 28).
\end{abstract}

Conforme a citação anterior, verificamos a confirmação do papel central que a violência ocupa nos contextos coloniais, violência esta que não diz respeito a uma dominação subjetiva do outro, mas que na verdade se constrói e concretiza por meio da subjugação e dominação dos corpos através da violência física. Dessa forma, é que, portanto, o mundo colonial é definido como sendo "um mundo compartimentado, maniqueísta, imóvel, mundo de estátuas: a estátua do general que efetuou a conquista [...] Mundo seguro de si, que esmaga com suas pedras os lombos esfolados pelo chicote. Eis o mundo colonial." (FANON, 2005, p. 39).

Revista de Letras JUÇARA, Caxias - Maranhão, v. 03, n. 02, p. 128 - 142, dez. 2019| 131 
Diante disso, e compreendendo que o que caracteriza o colonialismo não se trata de um mecanismo de imposição subjetiva, mas sim uma imposição e dominação que se efetiva por meio do domínio e controle dos corpos a partir da violência física, é que então pensamos o significado de tupinismo não como processo de influência ou empréstimo de elementos das línguas tupi sobre outras línguas, mas como o movimento de dominação de outras comunidades indígenas, pertencentes e não pertencentes ao tronco tupi, efetivado a partir da imposição de uma língua tupi através da violência física.

\section{A língua geral amazônica e/ou nheengatu}

Embora o "descobrimento" do Brasil tenha ocorrido em 1.500, segundo Stessuk (2009) a efetiva colonização do território brasileiro ocorreu apenas em 1532 com a fundação das vilas de São Vicente e Piratininga. Anteriormente a esse período "a relação entre os portugueses e os brasis baseava-se então apenas no escambo de artefatos europeus em troca de viveres da terra e paubrasil" (STESSUK, 2009, p. 97). Conforme o autor, nesse contexto de trocas comerciais os portugueses se propuseram a aprender as línguas nativas, em especial o tupi antigo, denominado também durante o século XVI de língua brasílica, que predominava na região litorânea do território "descoberto".

O tupi antigo, como toda língua, possuía algumas variedades marcadas diatopicamente, como o tupinambá, falado numa extensão territorial muito mais ampla que as localidades onde se falavam outras línguas. Em consonância com isso, e pensando no processo de formação da língua geral amazônica, Bessa Freire nos esclarece que:

Quando os primeiros colonos portugueses, que chegaram ao Pará em 1616, defrontaram-se entre as centenas de línguas indígenas da Amazônia - com o tupinambá, falado na costa do Salgado até a boca do rio Tocantins. Eles conseguiram estabelecer um nível razoável de comunicação com esses índios porque em Pernambuco e Maranhão, de onde vieram, haviam aprendido a falar a língua brasílica, nome dado aos jesuítas à língua tupinambá usada na catequese pelos jesuítas em todo litoral brasileiro desde o século XVI. (FREIRE 2011, p. 58-59) 
Nesse sentido, o autor nos mostra que o processo de constituição da língua geral amazônica ocorreu por meio do contato entre os portugueses que chegaram ao Pará, em 1616, com o tupinambá, falado na costa do Salgado até a boca do rio Tocantins. O estabelecimento de um nível razoável de comunicação entre os portugueses e os nativos ocorreu, pois os portugueses já haviam aprendido a falar a língua brasílica utilizada desde o século XVI pelos jesuítas durante a catequese.

Considerando isso e refletindo sobre tal processo, num primeiro momento nos parece que estamos diante de uma língua crioula, oriunda do contato entre o português e a língua tupinambá falada na costa do Salgado até a boca do rio Tocantis, contudo o próprio Bessa Freire traz em sua discussão as controvérsias apresentadas entre os estudiosos acerca do entendimento de se a língua geral é ou não um crioulo.

Quanto a isso, é importante levarmos em consideração, conforme assinala Freire (2011), que a existência de uma língua crioula implica necessariamente na constituição de uma língua mista, em que se percebem no léxico influências da língua "dominante", e na gramática traços da língua "dominada". Partindo desse pressuposto, observamos, entretanto que com a língua geral amazônica o processo ocorrido é o inverso, pois segundo Couto (1996), seu léxico é constituído a partir do tupi, ao passo que sua gramática se aproxima do português.

Para Bessa Freire:

A língua geral amazônica é uma das línguas de maior importância histórica no Brasil e, não obstante isso, sua história ao longo dos quatrocentos anos de conquista da Amazônia brasileira é muito pouco conhecida, e por isso mesmo, tem sido obscurecida por um grande número de equívocos e ideias preconcebidas. Esses equívocos e preconceitos afetam tanto sua natureza de língua específica, nitidamente distinta do idioma dos índios tupinambá do Maranhão e do Pará, no qual teve sua origem, e da outra língua geral que se desenvolveu no sudeste do Brasil, a língua geral paulista, quanto a história de sua extraordinária expansão como língua dominante durante dois séculos no estado do Maranhão e Grão-Pará, que, até a metade do século XVIII, foi outra colônia portuguesa distinta do que era então o estado do Brasil. (FREIRE, 2011, p. 13). 
Conforme a citação anterior é importante que se destaque que apesar de a língua geral amazônica ter sido originada da língua tipinambá do Maranhão e do Pará, trata-se de uma língua específica e, portanto, distinta do tupinambá. Essa distinção é pontuada por alguns estudiosos que de acordo com Freire (2011) chegam a propor duas nomenclaturas: tupinambá colonial que indica se tratar da língua geral em processo de expansão, e tupinambá tribal, que seria a língua falada pelas comunidades nativas, que até o final do século XVIII desaparecem definitivamente.

Em paralelo a este processo que estamos pontuando resumidamente em relação à formação da língua geral amazônica, mostra-se relevante apresentar ainda o percurso histórico trajado por esta língua. De acordo com Freire (2011), os processos de contato entre as línguas na região amazônica ocorreram de modo a transitar entre o monolinguismo e o bilinguismo, sendo que a construção de cidades, vilas e povoados também foram fatores que afetaram não apenas a espacialidade da região, mas se mostraram determinantes no processo de manutenção e inversamente declínio da língua geral amazônica.

Nas aldeias de origem, onde residiam às comunidades nativas, prevaleciam às línguas vernáculas faladas pelas comunidades indígenas. Ao passo, que nas vilas e povoados existiam duas possibilidades: aquele índio que se encontrava em condição de trânsito junto ás vilas e povoados era identificado como "índio manso", e fazia uso tanto da língua vernácula de sua comunidade, quanto da língua geral amazônica falada nos povoados. Por outro lado, aqueles índios que permaneciam nas vilas e povoados, considerados como "índios tapuios", deixavam sua língua materna, que não era utilizada nas relações estabelecidas nos povoados, em prol da língua geral amazônica, originando dessa forma uma situação de monolinguismo em língua geral. É neste momento histórico, conforme aponta Freire (2011), que se torna possível observar e constatar o caráter expansivo da língua geral amazônica.

Com o surgimento das cidades a situação se altera, e se outrora os processos de monolinguismo e biliguismo variavam somente entre línguas indígenas, isto é, monolinguismo na língua vernácula entre aqueles indígenas que viviam nas aldeias de origem, bilinguismo em língua vernácula e geral amazônica entre aqueles que se encontravam numa situação de trânsito junto às vilas e 
povoados, e monolinguismo em língua geral entre aqueles indígenas que residiam nas vilas e povoados, com o surgimento das cidades no cenário linguístico também surge à língua portuguesa.

Da mesma forma como aconteciam nas vilas e povoados, aqueles índios que estavam em situação de trânsito nas cidades, considerados "índios civilizados", faziam uso tanto da língua geral amazônica quanto da língua portuguesa, dando forma a um contexto bilíngue. Por sua vez, aqueles que permaneciam na cidade, identificados como "caboclo" (amazonense/paraense), faziam uso apenas da língua portuguesa que agora assumia a hegemonia nas relações estabelecidas nas cidades. Desse modo, é neste contexto histórico, conforme assinala Freire (2011), que verifica-se o processo de declínio da língua geral amazônica e expansão da língua portuguesa.

\section{A língua geral amazônica e/ou nheengatu: um instrumento para um processo de imposição?}

Que língua nós apagamos para termos uma língua nacional (o português)? De que língua (ou línguas) foi preciso nos distanciar historicamente e quais as línguas que tiveram de ser silenciadas para que obtivéssemos uma língua portuguesa? (ORLANDI, 1993, p. 56).

No texto intitulado La danza de las gramáticas: la relación entre el tupí y el portugués de Brasil, a pesquisadora Eni Orlandi propõe uma discussão bastante interessante ao nos convidar a refletir sobre os processos que levaram a construção de uma língua nacional (português). Nesse sentido, pode-se dizer ainda que são numerosos e convincentes os estudos que apontam como extremamente "cruéis" os meios que levaram a língua portuguesa a tornar-se a língua nacional no território brasileiro. Em consonância com isso, evidentemente que não propomos aqui ir de encontro a tais estudos, mas propomos tão somente uma releitura acompanhada de uma outra reflexão a partir dos questionamentos levantados por Orlandi.

Sendo assim, e se ao contrário de nos questionarmos sobre que língua(s) tivemos que apagar/silenciar para termos uma língua portuguesa, de modo muito semelhante nos questionássemos sobre quais línguas tivemos que apagar e 
silenciar para termos uma língua geral? Será que a resposta para tal questionamento se aproximaria da "crueldade" e "indiferença" ao uso linguístico do outro determinantes no processo de construção e expansão da língua portuguesa? São esses questionamentos que nos propomos discutir e responder a partir de agora.

\begin{abstract}
A reprodução inicial dessa língua ocorreu de forma quase espontânea. No entanto, passou a ser feita de forma mais sistemática e - digamos assim - planejada, com a catequese [...] A política de Portugal, até o final da década de 1720, foi de franco incentivo à expansão da língua geral, pelo que isso representava em termos de rentabilidade da colônia. Em vários momentos, o rei de Portugal repreendeu os carmelitas, os mercedários e os franciscanos da Amazônia, cujos missionários não eram tão fluentes na língua geral quanto os jesuítas (Sweet, 1974, p. 106). Através da Carta Régia de 30 de novembro de 1689, Portugal reconheceu a LGA como língua oficial do Estado do Maranhão e GrãoPará, determinando que os missionários deviam ensiná-la aos índios e aos próprios filhos dos portugueses concentrados nos embriões de núcleos urbanos que se formavam na região (Kiemen, 1954, p. 170). (FREIRE, 2011, p. 60-63).
\end{abstract}

Conforme a citação anterior, um ponto muito importante que precisa ser considerado em se tratando do processo de expansão e concentração da língua geral amazônica, diz respeito ao fato desse processo não ter ocorrido de forma isenta ao poderio e discurso colonial. Como se pode observar, para que o processo de disseminação e propagação da língua geral ocorresse de maneira sistêmica houve uma forma de intervenção institucional da coroa portuguesa, obrigando o ensino da língua geral tanto aos indígenas quantos aos filhos dos portugueses, de modo que podemos constatar que assim como o estado em Althusser (1985) legitima suas ideologias a partir de determinados aparelhos de controle, assim também a língua geral amazônica foi "legitimada" através do poder institucional representado pela coroa portuguesa.

Torna-se possível ainda que se questione o porquê de o colonizador ter optado por institucionalizar e apoiar a propagação de uma língua que não a sua, e a resposta para este questionamento nos parece relacionar-se a duas questões pontuadas por Freire (2011): Primeiro ao fato de o colonizador ter percebido logo nos primeiros contatos que a comunicação com os nativos era uma condição fundamental para sobrevivência na Amazônia; e em segundo lugar que os 
indígenas poderiam fornecer a força de trabalho necessária para tornar viável o projeto colonial.

De modo que para que isso acontecesse era preciso, antes de tudo, que se superassem a enorme diversidade linguística que caracterizava o ambiente, de maneira que para isso mostrava-se necessário o desenvolvimento de uma língua que permitisse o contato entre um vasto número de falantes, pertencentes ou não a mesma etnia. Indo ao encontro dessas necessidades, a língua geral amazônica cumpriu perfeitamente esse papel, pois conforme pontua Freire (2011), era uma língua considerada até mesmo supraétnica permitindo o contato entre povos de diferentes etnias.

Nessa perspectiva, revela-se importante refletirmos até que ponto, de fato, a língua geral amazônica permitiu o contato entre povos de diferentes etnias ou se mais precisamente tratava-se de uma "permissão" forçada, tendo em vista que nem todas as comunidades indígenas pertenciam ao tronco tupi, do qual a língua geral fazia parte. Nesse sentido, é relevante lembrar que os troncos linguísticos, segundo Freire (2011), que constituíam a Amazônia brasileira no século XVI eram: Tupi, Karib, Aruak, Pano, Tukano e Jê, de modo que considerando, portanto, a variedade desses troncos e línguas existentes em época, não nos parece desfocada a impressão de que a língua geral possa ter sido coercitiva e violentamente imposta sobre outras comunidades que não a tupinambá.

Partindo disso, é possível que se aponte que a forma como se efetivou a organização do trabalho indígena na Amazônia, por meio dos chamados descimentos, mostrou-se um fator de fundamental importância no processo de imposição da língua geral, pois, conforme destaca Freire (2011), os descimentos consistiam em expedições, em geral pacíficas, ainda que acompanhadas por escolta militar, realizadas com a presença de missionários que tinham por objetivo convencer os indígenas a deixarem suas aldeias de origem e migrarem para as aldeias de repartição situadas nas proximidades dos núcleos coloniais.

As aldeias de repartição, por sua vez, eram núcleos artificiais, "onde índios de diferentes línguas e de culturas diversificadas eram estocados para ser alugados e distribuídos - repartidos entre os colonos, os missionários e o serviço real da coroa portuguesa". (FREIRE, 2011, p. 76). Nas aldeias de repartição, 
configuradas a partir de um cenário totalmente indiferente às especificidades linguísticas e culturais de cada comunidade, só restava espaço para uma única língua, evidentemente a língua geral amazônica, que aos poucos assumia o papel e as funções das línguas vernáculas das comunidades que saiam das aldeias de origem.

No confronto com a língua geral, muitas línguas minoritárias foram condenadas à extinção, porque foram sendo gradualmente abandonadas em seus usos e funções de língua materna pelos índios nascidos nas aldeias de repartição, sobretudo por causa do extermínio físico de seus falantes. (FREIRE, 2011, p. 74 grifo nosso).

Conforme essa citação, observa-se que a apropriação e expansão da língua geral não ocorreu de maneira romântica e pacífica, muito pelo contrário, num cenário construído sob o espaço para somente uma língua, as demais línguas faladas por comunidades indígenas, pertencentes ou não ao tronco tupi, foram aos poucos sendo suplantadas por uma língua que apesar de não ser o português era percebida pelos indígenas como uma "língua de branco" e, portanto, do colonizador.

É possível verificarmos ainda que a escola, atuando como aparelho institucional, também teve importante participação na difusão e imposição da língua geral, haja vista que, segundo Freire (2011), todo o ensino era ministrado exclusivamente por missionários, através da língua geral, não havendo registro de professores indígenas durante a época colonial, de maneira que os saberes indígenas, as culturas, as línguas e as especificidades de cada grupo ficavam sempre excluídas da escola - com exceção é claro da língua geral amazônica.

Em consonância com isso, observamos que o uso da língua geral na escola, até meados do século XVIII, "representou para os grupos de filiação linguística não tupi uma imposição arbitrária do poder colonial, que empregou, para isso, a palmatória, diferentes tipos de castigo e outras formas de violência física". (FREIRE, 2011, p. 62 grifo nosso). Ainda segundo o autor:

"Vários relatos dão conta da resistência de algumas índias, que se recusavam a trocar sua língua materna pela língua geral, sendo 
espancadas pelo missionário responsável pela escola com uma palmatória até lhe incharem as mãos e arrebentar o sangue". (FREIRE, 2011, p. 62 grifo nosso).

Considerando isso, somos levados ao entendimento de que o uso da língua geral no contexto amazônico não foi tão romântico como se parece, ao ponto de nos fazer pensar que somente a língua portuguesa tenha sido imposta, mas, antes, culminou também num processo violento de desapropriação linguística entre diversas comunidades que não "optaram" pela língua geral. De modo que mostra-se necessário refletirmos sobre o que significa, de fato, esse processo de desapropriação/apagamento linguístico, já que para alguns pode ser que no contexto tratado neste artigo não simbolize nada, justificando isso por meio da ideia de que houve "simplesmente" uma substituição de códigos, ao passo que a língua de origem indígena permanecia.

Entretanto, considerando que de acordo com Hall (2016) a linguagem pode ser representada como um repositório de valores e significados culturais, e nessa perspectiva, as línguas passam também a representar os valores, identidade, e cultura de um povo, de modo que quando uma comunidade perde uma língua, perde-se, portanto, igualmente um conjunto de valores identitários e culturais resguardados por aquela língua, podemos então concordar que "Quando uma língua deixa de existir, perdemos mais do que um sistema gramatical ou de comunicação complexo e estruturado; perdemos uma maneira de ver e compreender o mundo". (OTHERO, 2017, p. 112).

Além disso, no contexto das cosmologias indígenas cujas as línguas representam muito mais que funções sociais:

Importa também destacar a importância vital e simbólica da língua para os povos indígenas, por meio da qual estabelecem as conexões com a natureza e com o mundo. Assim, a língua é um fenômeno de comunicação sociocósmica de vital importância na relação recíproca entre sociedades humanas e estas com os seres não humanos da natureza. Nesse sentido, a perda de uma língua por um povo indígena afeta diretamente a relação desse povo com a natureza e com o cosmo, resultando em quebra ou redução de conectividade entre os seres e, consequentemente, afetando o equilíbrio e a harmonia da vida no mundo. (BANIWA, 2016, p. 44-45). 
Desse modo, partindo do fato de que muitas línguas foram perdidas e suplantadas em detrimento do uso da língua geral amazônica, e compreendendo que a perda de uma língua não se restringe meramente a perda de um conjunto de códigos que permitem a comunicação, mas, por outro lado, significa a perda de uma série de valores, formas de apreender o mundo e identidades que marcam e configuram uma coletividade, consideramos igualmente importante refletirmos não somente acerca das causas que culminaram numa língua nacional, mas também sobre quantas e quais línguas tiveram que ser silenciadas/apagadas para que tenha existido uma língua geral.

Portanto, concluímos que para além de uma língua supraétnica que permitiu o contato entre povos de diferentes etnias, na realidade a língua geral foi durante certo tempo um forte instrumento utilizado segundo os interesses do sistema colonial, e cuja a imposição, ainda que diferente dos meios utilizados que culminaram com a hegemonia da língua portuguesa, não deixou de ser arbitrária, coercitiva e violenta, desconsiderando as especificidades, identidades, singularidades e o direito de cada comunidade em manter sua própria língua.

\section{Considerações Finais}

À vista do que foi discutido ao longo desse artigo, para além de problematizar os processos de implantação, ou para ser mais preciso imposição da língua geral amazônica na região da Amazônia brasileira, e desde já reconhecendo que não nos debruçamos enfaticamente sobre tais processos, pois a intenção desta escrita consistiu apenas em demonstrar que houve uma forma coercitiva e violenta de imposição da língua geral sobre outras comunidades, esperamos com isso ter possibilitado uma outra leitura que nos convida a refletirmos não apenas acerca da imposição da língua portuguesa sobre comunidades indígenas, mas pensar no processo de imposição linguística como algo que ocorreu também a partir de uma língua indígena, cujos meios que culminaram com sua propagação se mostram muito próximos da violência do processo colonial que findou com a hegemonia da língua portuguesa no Brasil.

Também é necessário pontuar aqui que a palavra tupinismo, com a carga semântica utilizada nesse estudo, não se refere à imposição de todas as línguas 
do tronco do tupi ou mesmo do tronco linguístico sobre outras línguas ou troncos, mas refere-se aos processos que entendemos como impositivos e violentos de disseminação e expansão da língua geral amazônica; processos estes, que como procuramos comprovar caracterizam-se perfeitamente no escopo do colonialismo por terem como base/motor a violência física.

Desse modo, encerramos defendendo que cabe, portanto, também nos questionarmos sobre quais línguas tivemos que apagar/silenciar e nos afastar historicamente para que tenha existido uma língua geral, pois se a perda de uma língua representa muito mais que a perda de um sistema partilhado socialmente, significando também a perda de elementos identitários, culturais e, ainda, no contexto das cosmologias indígenas uma ruptura com o próprio cosmos, então a imposição da língua geral amazônica realmente foi algo problemático, tendo em conta que muitas comunidades e etnias indígenas com suas línguas próprias e consequentemente costumes, culturas e identidades, foram violentamente obrigadas a observarem suas línguas e costumes sendo aos poucos suplantados pela língua geral amazônica.

\title{
TUPINISM: A STUDY ON THE IMPOSITION OF THE AMAZON GENERAL LANGUAGE IN THE BRAZILIAN CONTEXT
}

\begin{abstract}
Understanding by Tupinism the process of imposition through the physical violence of a Tupi trunk language, this study seeks to demonstrate that the means of implantation and propagation of the general Amazonian or Nheengatu language in the Brazilian Amazon occurred in an imposing and coercive manner. Thus, the starting point for the discussions is the contributions of Antezana (2014), Baniwa (2016), Fanon (2005), Freire (2011), Fonseca (2015), Hall (2016), Othero (2017), Silva and Isquerdo (2009) and Stessuk (2006). Thus, it was possible to verify that besides a supra-ethnic language that allowed the contact between peoples of different ethnic groups, in reality the general Amazonian language was, for some time, a strong instrument used according to the interests of the colonial system, whose imposition did not allow to be arbitrary, coercive and violent, thus disregarding the specificities, identities, singularities and the right of each community to maintain its own language.
\end{abstract}

Keywords: Amazonian general language. Propagation mechanisms. Linguistic Imposition.

\section{Referências}

ALTHUSSER, L. Aparelhos Ideológicos do Estado: nota sobre aparelhos ideológicos do Estado. Rio de Janeiro: Edições Graal, 1985.

\section{ANTEZANA, Marta Batista Ordoñez. A gramatização da língua portuguesa do} Brasil: o tratamento da variedade brasileira do português na grammatica 
portugueza (curso superior) de João Ribeiro. 2014. 165 f. Tese (Doutorado em Letras) - Programa de pós-graduação em Letras, Universidade de São Paulo (USP), São Paulo, 2014.

BANIWA, Gersem. Língua, educação e interculturalidade na perspectiva indígena. In: ALBUQUERQUE, Gerson Rodrigues. (Org). Das Margens. Rio Branco: Nepan Editora, 2016. p. 41-56.

COUTO, Hildo H. Introdução ao estudo das línguas crioulas e pidgins. Brasília, UNB, 1996.

FANON, Frantz. Os condenados da terra. Juiz de Fora: UFJF, 2005.

FREIRE, José Ribamar Bessa. Rio Babel: A história das Línguas na Amazônia. $2^{\circ}$ ed. Rio de Janeiro: EduUERJ, 2011.

FONSECA, Danilo Ferreira da. Colonialismo, independência e revolução em Frantz Fanon. Revista África e Africanidades - Ano 7 - n. 19. abr. 2015.

HALL, Stuart. Cultura e Representação. Trad. Daniel e William Oliveira. Rio de Janeiro: Ed. PUC-Rio; Apicuri, 2016.

HOUAISS, Antônio. Dicionário Houaiss da Língua Portuguesa. Rio de Janeiro: Objetiva, 2009.

ORLANDI, Eni $P$. La danza de las gramáticas. La relación entre el tupi y el portugués de Brasil. Iztapalapa, 29 (13): 54-74, México, 1993.

OTHERO, Gabriel de Ávila. Mitos de Linguagem. São Paulo: Parábola Editorial, 2017.

SAID, E. W. Cultura e Imperialismo. Trad. Denise Bottmann. São Paulo:

Companhia das Letras, 2011.

SILVA, Daniela de Souza; ISQUERDO, Aparecida Negri. Tupinismos na língua falada nas capitais da região centro-oeste documentados pelo projeto ALIB. In: Dermeval da Hora (org.). Anais - VI Congresso Internacional da Abralin. João Pessoa: Ideia, 2009. p. 971-980.

STESSUK, Sílvio. A implantação da Língua Portuguesa no Brasil, em contato com o Tupi antigo e as Línguas Africanas. TODAS AS LETRAS I, volume 8, n.1, 2006.

Data da Submissão:14/11/2019

Data da Aprovação: 26/12/2019 